MPA and 1 with GPE (Patients characteristics are described in Table 1). From the 59 patients with GPA according to clinical judgment, 34 fullfilled the ACR 1990 criteria $(57,63 \%)$ whereas 51 (86,44\%) fullfilled the ACR/EULAR 2007 criteria. From the 33 patients diagnosed as having MPA $9(27,27 \%)$ and and $3(9.09 \%)$ fulfilled classification criteria for GPA according to ACR 1990 criteria and 2017 ACR/EULAR preliminary criteria, respectively. The patient with GPE did no classify as GPA by either set of criteria. The values for Sensibility, Espicifity, LR+ LR-, PPV and NPV in our population for both Criteria sets, are described in table 2.

Table 1. Patient characteristics

\begin{tabular}{|l|l|l|l|l|l|}
\hline & N & Gender (F) & $\begin{array}{l}\text { Age, Av } \\
\text { (S.D.) }\end{array}$ & $\begin{array}{l}\text { ACR } \\
1990+ \\
\text { for GPA }\end{array}$ & $\begin{array}{l}\text { ACR/ } \\
\text { EULAR } \\
2017+ \\
\text { for GPA }\end{array}$ \\
\hline GPA & $59(63.44 \%)$ & $30(50.85 \%)$ & $\begin{array}{l}46.54 \\
(13.32)\end{array}$ & $\begin{array}{l}34 \\
(57,63 \%)\end{array}$ & $\begin{array}{l}51 \\
(86,44 \%)\end{array}$ \\
\hline MPA & $33(35.48 \%)$ & $23(69.7 \%)$ & $\begin{array}{l}62,72 \\
(2.11)\end{array}$ & $\begin{array}{l}9 \\
(27,27 \%)\end{array}$ & $3(9,09 \%)$ \\
\hline GPE & $1(1.08 \%)$ & 1 & 62 & 0 & 0 \\
\hline Total & 93 & $39(41.94 \%)$ & $\begin{array}{l}52,45 \\
(14.97)\end{array}$ & $\begin{array}{l}43 \\
(46,24 \%)\end{array}$ & $\begin{array}{l}54 \\
(58,06 \%)\end{array}$ \\
\hline
\end{tabular}

Table 2.- Performance of ACR 1999 and ACR/EULAR preliminary Criteria for GPA in Chilean Patients

\begin{tabular}{|l|l|l|}
\hline GPA Clasification Criteria & ACR 1990 & $\begin{array}{l}\text { ACR/EULAR 2017, } \\
\text { preliminary Criteria }\end{array}$ \\
\hline Sensitivity & $57,6 \%$ & $91,5 \%$ \\
\hline Especificity & $70,6 \%$ & $91,2 \%$ \\
\hline Positive Predictive Value & $77,3 \%$ & $94 \%$ \\
\hline Negative Predictive Value & $49 \%$ & $86 \%$ \\
\hline Positive Likelihood Ratio & 1,96 & 10,3 \\
\hline Negative Likelihood Ratio & 0,6 & 0,9 \\
\hline accuracy & 0,62 & 0,91 \\
\hline
\end{tabular}

Conclusions: In our population, provisional 2017 ACR/EULAR criteria for classificatión of GPA have better acurracy than ACR 1990 classification criteria.

References:

[1] -Leavitt RY, Fauci AS, Bloch DA, Michel BA, Hunder GG, Arend WP, Calabrese LH, Fries JF, Lie JT, Lightfoot RW Jr, et al.The American College of Rheumatology 1990 criteria for the classification of Wegener's Granulomatosis. Arthritis Rheum 1990;33:1101-7.

[2] -Luqmani, R, Merkel, P. New Clasification Criteria for ANCA-Associated Vasculitis: Implication for Clinical Practice. Lecture, 2016 ACR/ARHP Annual Metting.

Disclosure of Interest: None declared

DOI: 10.1136/annrheumdis-2017-eular.6732

\section{AB0591 EFFICACY AND SAFETY PROFILE OF INTRAVENOUS CYCLOPHOSPHAMIDE TREATMENT IN ELDERLY PATIENTS WITH SYSTEMIC VASCULITIS}

S. Shimoyama ${ }^{1}$, T. Kurita ${ }^{1}$, S. Fukaya ${ }^{2}$, M. Kanda ${ }^{2}$ on behalf of Japanese Red Cross Kitami Hospital, Hokkaido P.W.F.A.C. Obihiro Kosei Hospital. ${ }^{1}$ Internal medicine/ General medicine, Japanese Red Cross Kitami Hospital, Kitami; ${ }^{2} 3 r d$ Department of Internal medicine, Hokkaido P.W.F.A.C. Obihiro-Kosei General Hospital, Obihiro, Japan

Background: Intravenous cyclophosphamide is mainstay of remission induction and dose reduction of glucocorticoid in patients with systemic vasculitis. However, little evidence has yet shown the safety profile of intravenous cyclophosphamide, especially in elderly patients.

Objectives: To evaluate efficacy and safety of patients diagnosed as systemic vasculitis and treated with intravenous cyclophosphamide.

Methods: This retrospective study comprised the patients with active systemic vasculitis who were admitted to Kitami Red Cross Hospital and Obihiro-Kosei General Hospital from April 2009 to March 2016. These patients were treated with intravenous cyclophosphamide plus conventional therapy (IVCY group) or only with conventional therapy (glucocorticoid/azathioprine/tacrolimus and methotrexate) (conventional therapy group). The patients treated with oral cyclophosphamide or rituximab were excluded. Primary endpoint was defined as death or serious infections. Prognostic factors in IVCY group were analyzed by multivariate Cox regression methods.

Results: This study comprised 90 patients with active systemic vasculitis (61 microscopic polyangiitis, 9 eosinophilic granulomatosis with polyangiitis, 10 granulomatosis with polyangiitis, and 10 polyarteritis nodosa). Fifty-one patients were over 70-year-old (26 patients in IVCY group). The mean observation period was 30.1 months. IVCY group had a trend for higher event-free survival rate as compared with conventional therapy group $(p=0.19)$. IVCY group had significantly higher cumulative survival rate as well $(\mathrm{p}=0.04)$. Age ( $\mathrm{HR}=1.07,95 \% \mathrm{Cl} 1.01-$ 1.14, $\mathrm{p}=0.03$ ), five factor score ( $F F S, H R=3.39,95 \% \mathrm{Cl} 1.36-8.44, \mathrm{p}=0.01)$ and glucocorticoid dose at 24 weeks (GC24, HR=1.14, 95\% Cl 1.05-1.22, $\mathrm{p}=0.001$ ) were identified as risk factors for events. In patients over 70-year-old, IVCY group had a trend for higher cumulative survival rate as well $(p=0.07$, Figure1). FFS $(\mathrm{HR}=3.30,95 \% \mathrm{Cl} 1.19-9.15, \mathrm{p}=0.02)$ and $\mathrm{GC} 24(\mathrm{HR}=1.10,95 \% \mathrm{Cl} 1.02-1.20$, $\mathrm{p}=0.01$ ) were identified as risk factors for events.

Table 1. Background of patients with IVCY group and conventional therapy group

\begin{tabular}{lccc}
\hline & IVCY group $(\mathrm{n}=54)$ & conventional therapy group $(\mathrm{n}=36)$ & P value \\
\hline MPA,n $(\%)$ & $36(67 \%)$ & $25(69 \%)$ & 0.95 \\
EGPA, $\mathrm{n}(\%)$ & $6(11 \%)$ & $3(8 \%)$ & 0.56 \\
GPA, $(\%)$ & $8(15 \%)$ & $2(6 \%)$ & 0.36 \\
PN,n $(\%)$ & $4(7 \%)$ & $6(17 \%)$ & 0.19 \\
age $(\mathrm{y})$ & $66.4 \pm 15.5$ & $72.3 \pm 15.9$ & 0.09 \\
Male, $n(\%)$ & $19(35 \%)$ & $13(36 \%)$ & 0.93 \\
FFS $(\mathrm{d}=0)$ & $0.6 \pm 0.7$ & $0.7 \pm 0.8$ & 0.40 \\
BVAS $(\mathrm{d}=0)$ & $10.9 \pm 5.5$ & $10.5 \pm 6.4$ & 0.71 \\
PSL $(\mathrm{mg}, \mathrm{d}=0)$ & $50 \pm 11$ & $38 \pm 13$ & 0.39 \\
PSL pulse, $\mathrm{n}(\%)$ & $18(33 \%)$ & $22(61 \%)$ & 0.01 \\
AZA,n $(\%)$ & $13(24 \%)$ & $14(39 \%)$ & 0.10 \\
MTX,n $(\%)$ & $2(4 \%)$ & $4(11 \%)$ & 0.17 \\
\hline
\end{tabular}

Abbreviation: MPA (microscopic polyangiitis), EGPA (eosinophilic granulomatosis with polyangiitis), GPA (granulomatosis with polyangiitis), PN (polyarteritis nodosa), BVAS (Birmingham Vasculitis Activity Score), AZA (azathioprine), MTX (methotrexate), $d=0$ means day 0 ; the start of the treatment.

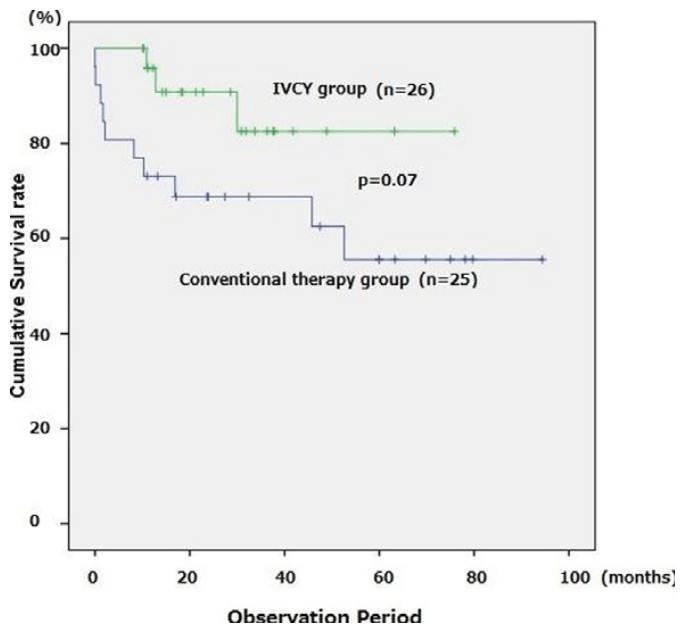

Conclusions: Intravenous cyclophosphamide treatment had acceptable safety profile even in elderly patients.

Disclosure of Interest: None declared

DOI: 10.1136/annrheumdis-2017-eular.3338

\section{AB0592 PULMONARY ARTERY ANEURYSM IN BEHÇET'S DISEASE: RETROSPECTIVE MONOCENTRIC TUNISIAN STUDY}

S. Hammami, A. Sondes, R. Klii, M. Kechida, M. Ben Nasr, I. Kochtali. Internal medicine, University Hospital F Bourguiba Monastir, Monastir, Tunisia

Background: Behcet's disease (BD) is a chronic inflammatory disorder. Arterial inflammatory involvement includes predominantly aortic and pulmonary aneurysmal lesions, affects about $10 \%$ of patients with BD. They account for the severity of the disease and are a leading cause of death

Objectives: To investigate the frequency of Behcet's disease with pulmonary artery aneurysm (PAA). We aimed to review PAA and other systemic involvements associated with PAA in $\mathrm{BD}$ and to provide a review of diagnostic techniques, treatment and prognosis

Methods: 243 BD patients were recruited for this study (152 men, 91 women, mean age $31.7 \pm 7$ years. Diagnosis of BD was made according to the international study group for Behçet's disease [International Study Group for Behçet's Disease, lancet 1990; 335: 1078-80]. All patients underwent full clinical examination, routine laboratory investigations. Chest X-rays and pulmonary CT angiography were performed on all patients with pulmonary involvement.

Results: Eight of the patients have pulmonary aneurysm, all of them are male, mean age $32.6 \pm 13$, The mean disease duration until PAA appear was $2.8 \pm 3.5$ years. The main pulmonary symptoms were as follows: dyspnea $87 \%$, cough $50 \%$, hemoptosis: $75 \%$, fever $37 \%$. Other systemic involvements associated PAA are as follows: buccal (100\%) and genital (75\%) ophthalmic $25 \%$, neurological $50 \%$, cardiac $25 \%$. 3 patients presented with Hughes Stovin syndrome. The treatment includes corticosteroids, colchicine and immunosuppressant agents (Cyclophosphamid or azathioprine), only two patients reveive coil embolization. At follow up for a median of 4 years ( 1 to 25 years), three patients died because they stopped their medication.

Conclusions: The prognosis of PAA is poorer than other lesions involved in $\mathrm{BD}$, treatment (immunosuppressant agents, colchicine) seems to improve the prognosis. It is important to maintain the immunosuppressive therapy and a regular follow-up to prevent these complications 